\title{
Nutritional status of children in a malaria meso endemic area: cross sectional study on prevalence, intensity, predictors, influence on malaria parasitaemia and anaemia severity
}

Irene Ule Ngole Sumbele ${ }^{1 *}$, Orelien S. Mtopi Bopda ${ }^{1}$, Helen Kuokuo Kimbi ${ }^{1}$, Teh Rene Ning ${ }^{1}$ and Theresa Nkuo-Akenji ${ }^{2}$

\begin{abstract}
Background: The contradictory results on the interaction between nutritional status and malaria warrants further investigation in various epidemiological settings, to assert the antagonistic or synergistic relationship. This study examines the prevalence, severity and predictors of malnutrition and its influence on malaria parasitaemia and anaemia severity in children in the Mount Cameroon area.

Methods: A cross-sectional study involving 454 children $\leq 14$ years was carried out from February to May 2013 in Muea community. Anthropometric measures of malnutrition (z-scores $<-2$ standard deviations below mean) were obtained and spleen size assessed. The prevalence and density of malaria parasites were determined and haemoglobin concentration and white blood cell count obtained using an automated haematology analyzer. Univariate and multivariate analyses were used to evaluate influence of malnutrition on anaemia, malaria parasitaemia and predictors respectively.
\end{abstract}

Results: The overall prevalence of malnutrition was $22.8 \%$, with stunting being the most common form (17.1\%), followed by underweight $(8.2 \%)$ and wasting (5.5\%). Stunting was significantly higher $(P<0.01)$ in males $(23.1 \%)$ than in females $(11.9 \%)$. The prevalence of malnutrition was significantly highest $(P=0.03)$ in children $\leq 5$ years old $(29.5 \%)$ than their counterparts. Severe stunting, wasting and underweight were prevalent in $4.9 \%, 1.6 \%$ and $1.8 \%$ of the children respectively. Clinical malaria parasitaemia was significantly higher $(P=0.01)$ in children who were stunted (16.9\%) and underweight (21.6\%) than their normal counterparts (7.5\%; $8.2 \%$ respectively). The model demonstrated sex $(P=0.006)$ and age group 1.1-3 years $(P=0.03)$ as significant predictors of malnutrition. In children who were malaria parasite negative, the prevalence of anaemia as well as severities were significantly higher ( $P=0.04$ and $P=0.001$ respectively) in those malnourished.

Conclusions: The presence of stunting in the community significantly augmented the prevalence and clinical presentation of Plasmodium infection. Malnutrition enhanced the severity of anaemia in malaria parasite negative children hence, their health and growth potential needs to be improved upon.

Keywords: Malnutrition, Stunting, Wasting, Underweight, Malaria, Children, Anaemia, Prevalence, Predictors

\footnotetext{
* Correspondence: sumbelei@yahoo.co.uk

'Department of Zoology and Animal Physiology, University of Buea, Buea, Cameroon

Full list of author information is available at the end of the article
}

(c) 2015 Sumbele et al. Open Access This article is distributed under the terms of the Creative Commons Attribution 4.0 International License (http://creativecommons.org/licenses/by/4.0/), which permits unrestricted use, distribution, and reproduction in any medium, provided you give appropriate credit to the original author(s) and the source, provide a link to the Creative Commons license, and indicate if changes were made. The Creative Commons Public Domain Dedication waiver (http://creativecommons.org/publicdomain/zero/1.0/) applies to the data made available in this article, unless otherwise stated. 


\section{Background}

In developing countries, including those in sub-Saharan Africa, malnutrition represents an additional burden and often co-exists with malaria [1]. While under nutrition increases the general susceptibility of an individual to viral, bacterial and parasitic infections [2, 3], infections negatively impact on the nutritional status, resulting in a vicious cycle of under nutrition and infection $[4,5]$. Synergism between malnutrition and infection is responsible for much of the excess mortality among individuals in less developed regions.

Nutritional status may be assessed by subjective clinical evaluation, or by the use of anthropometric indicators and reference standards to determine poor nutritional status based on low weight-for-age (underweight), low heightfor-age (stunting), or low weight-for-height (wasting). Wasting is considered a manifestation of acute malnutrition, whereas stunting represents long-term malnutrition [6]. Undernutrition among children is a critical problem because its effects are long lasting and go beyond childhood. There is growing evidence that the health and nutrition of young children has a long-term effect on their cognitive development [7]. Stunting, which is the main type of malnutrition in young children, has been associated with impaired cognitive development, reduced academic achievement, and decreased physical work capacity in adulthood, with negative consequences on economic development of societies [8]. Stunting and wasting have also been strongly associated with the risk of death in children [9].

The influence of nutrition on the disease burden of malaria is unclear. The contradictory results on the interaction between nutritional status and malaria [10, 11], warrants further investigation in various epidemiological settings, to assert the antagonistic or synergistic relationship. Knowledge on the burden of stunting and other nutritional indices are lacking in children in the Mount Cameroon area where malaria is a major public health problem. This study examines the prevalence, severity and predictors of malnutrition and its influence on malaria parasitaemia and anaemia severity in children in the Mount Cameroon area.

\section{Methods}

\section{Study area and participants}

The study was carried out in Muea, a semi-rural setting in the rain forest ecozone on the Eastern flank of the active volcanic Mount Cameroon. The coordinates of the study area ranged from altitude $540 \mathrm{~m}$, latitude $04^{\circ}$ $10.464^{\prime} \mathrm{N}$, longitude $009^{\circ} 18.168^{\prime} \mathrm{E}$ to $556 \mathrm{~m}, 04^{\circ} 10.015^{\prime}$ $\mathrm{N}$ and $009^{\circ} 18.009^{\prime} \mathrm{E}$. Muea is about $29 \mathrm{~km}$ from the Atlantic Ocean, has an equatorial climate with relative humidity of above $80 \%$, a temperature range of $18-28{ }^{\circ} \mathrm{C}$ and an annual rainfall of about $4096 \mathrm{~mm}$. The rainy season characterised by frequent light showers, spans from March to October. The dry season runs from November to February. Plasmodium falciparum accounts for up to $96 \%$ of malaria infections in this area [12]. Muea has a heterogeneous and multiethnic population with about 3500 children $<14$ years old. The children from the community who participated in the study weighed $>5 \mathrm{~kg}$, were $\leq 14$ years old, free from other clinical conditions not related to malaria and sickle test negative. Children who presented with fever, joint pains, headache, malaise, abdominal pain, nausea, and vomiting were considered to be symptomatic.

\section{Study design}

A cross-sectional study was carried out from February 2013 to May 2013, which included the rainy season reported as the peak malaria transmission period in the Mount Cameroon Region [13]. After obtaining ethical clearance, administrative and local authorizations for the study, the team with the help of the health personnel proceeded to the field for sample collection. The collection of samples commenced a week following the deworming of the children in schools and community as a national health policy by officials from the Ministry of Public Health. Before start of the study, the parents, guardians and children were sensitized at their various quarters. A total of 500 children were randomly selected from the ten quarters in the study area by drawing from a list of homes with children less than 15 years of age. Briefly, the homes with children less than 15 years of age as well as the number of children in each of the homes were listed. The total number of children was randomly selected by drawing lots from the names listed. Consent forms were sent through the community health worker to parents and guardians of children in the selected homes seeking their consent/assent to participate in the study. Only the 454 children who presented a signed consent/assent form or verbal consent from parent or guardian took part in the study. The sample size for the study was calculated using the $85.4 \%$ prevalence of malaria in children in the study area in 2006 [14]. The sample size was determined using the formula $n=\mathrm{z}^{2} \mathrm{pq} / \mathrm{d}^{2}$ [15] where $n=$ the sample size required, $z=1.96$ : confidence level test statistic at the desired level of significance, $p=85.4 \%$ : proportion of malaria prevalence, $\mathrm{q}=1-\mathrm{p}$ : proportion of malaria negative children and $\mathrm{d}=$ acceptable error willing to be committed. The minimum sample size was estimated as $n=192$. This was adjusted to an optimum of at least 400 samples taking into consideration the decline in malaria parasite prevalence in the Mount Cameroon area [16] as well as for comparability with previous studies carried out in the area. The investigation methods included clinical evaluation and laboratory investigations. 


\section{Clinical evaluation}

Clinical evaluation was carried out by trained medical personnel. The clinical evaluation consisted of measurement of body temperature and examination of the spleen. Axillary body temperature was measured using a digital thermometer. A child with a body temperature $\geq 37.5{ }^{\circ} \mathrm{C}$ was considered febrile. The tip of the spleen was felt by pressing the abdomen under the left coastal border and splenomegaly was graded according to the classification of Hackett [17]. Ages of the children were obtained from their mothers and verified from their birth certificates. Weight and height were measured using a Hamson scale balance and a measuring tape respectively. Height-for-age (HA), weight-for-age (WA) and weight-for-height (WH) standard deviation (SD) scores (z scores) were computed based on the National Centre for Health Statistics (NCHS)-WHO growth reference curves using the nutrition module of the Epi Info 2000 programme [18]. Underweight was defined as a weight-for-age $\mathrm{z}$ (WAZ) score of $<-2$; wasting as a weight-for-height $\mathrm{z}$ (WHZ) score of $<-2$ and stunting as height-for-age $\mathrm{z}(\mathrm{HAZ})$ score of $<-2$. A child was identified as being malnourished if he or she scored $<-2$ in one of the anthropometric indices HA, WA and WH indices. $\mathrm{Z}$ scores of $<-3$ indicated severe wasting, severe stunting or severe underweight [19].

\section{Laboratory methods}

Approximately $4 \mathrm{~mL}$ of venous blood was collected from each participant into sterile disposable syringe and used for the preparation of thick and thin blood films. The remaining blood was dispensed into labelled ethelenediaminetetraacetate (EDTA) tubes. Labelled blood samples were transported on ice in a cool box of temperature between $8-10{ }^{\circ} \mathrm{C}$ to the University of Buea Malaria Research Laboratory for further analyses. The thick and thin blood films prepared on glass slides at the time of blood sampling were stained with Giemsa and examined following standard protocols [20]. Parasite density was determined on the bases of number of parasites per 200 leukocytes on thick blood film with reference to participants' white blood cell (WBC) count. If gametocytes were seen, the count was extended to 500 leukocytes [21]. A complete blood count including values for WBC and haemoglobin $\mathrm{Hb}$ ) concentration were obtained using an auto haematology analyser, the Beckman Coulter counter (URIT 3000), following the manufacturer's instructions. Anaemia was defined as $\mathrm{Hb}<11 \mathrm{~g} / \mathrm{dL}$ [20]. Asymptomatic malaria parasitaemia (AMP) was defined as the presence of Plasmodium with an axillary temperature of $<37.5{ }^{\circ} \mathrm{C}$ while clinical malaria parasitaemia (CMP) was defined as the presence of any species of Plasmodium, with an axillary temperature of $\geq 37.5{ }^{\circ} \mathrm{C}$ or reported fever in previous $48 \mathrm{~h} /$ headache/joint paint.

\section{Statistical analysis}

Data was entered into spread sheets using Microsoft Excel and analysed with the Statistical Package for Social Sciences (SPSS) version 19 (IBM - SPSS, Inc, Chicago, IL, USA). Data were summarized into means and standard deviations, and percentages were used in the evaluation of the descriptive statistics. Proportions were compared using the Chi-square test $\left(\chi^{2}\right)$. Differences between group means were compared using non parametric test, the Mann-Whitney $U$ test. Malaria parasite counts were log transformed before analysis. A binomial logistic regression model analysis was conducted to predict factors associated with malnutrition with sex, age groups, spleen size, anaemic and parasite status as independent variables. The interaction among confounders was also examined. Significant levels were measured at $95 \%$ confidence interval $(\mathrm{CI})$ with significant differences set at $P<0.05$.

\section{Ethical consideration}

Administrative clearance was obtained from the South West Regional Delegation of Public Health. The institutional review board hosted by the Faculty of Health Sciences, University of Buea issued the ethical clearance document. Further authorization was obtained from the chief and quarter heads of the Muea community. During sensitisation at the beginning of the study, the protocol was explained and the benefits of participating in the study highlighted. Children were enrolled into the study only when parent or guardian signed the assent form or gave a verbal consent. The participation of the children in the study was voluntary.

\section{Results}

\section{Characteristics of the study participants}

A total of 454 children with a mean \pm SD age of $6.7 \pm$ 3.4 years of both sexes residing in Muea in the Mount Cameroon area were evaluated for the prevalence and intensity of malnutrition and its influence on malaria parasitaemia and anaemia severity. Out of the 454 children examined, 211 (46.5\%) were males while 243 (53.5\%) were females. Only 451 children had complete anthropometric measurements. The mean \pm SD of HAZ, WAZ and WHZ scores were $-0.58 \pm 1.7,-0.40 \pm 1.3$ and $0.06 \pm 1.5$ respectively. The overall prevalence of malnutrition in the study population was $22.8 \%(\mathrm{CI}=19.2$ $26.9 \%$ ), with stunting being the most common form (17.1\%, CI $=13.9-20.8 \%)$, followed by underweight (8.2\%, CI $=6.0-11.1 \%)$ and wasting $(5.5 \%, \mathrm{CI}=3.8$ $8.1 \%)$ as shown in Table 1.

\section{Malnutrition in study population}

As revealed in Table 2, more males (29.3\%, CI $=23.6-$ $35.8 \%$ ) were malnourished when compared with females 
Table 1 Demographic and clinical characteristics of study participants

\begin{tabular}{|c|c|c|}
\hline \multicolumn{2}{|l|}{ Characteristic } & All \\
\hline \multicolumn{2}{|c|}{ Mean age in years (Range) } & $6.7 \pm 3.4(0.5-14)$ \\
\hline \multirow[t]{3}{*}{ Age groups (years) } & $\leq 5(\%)$ & $177(39)$ \\
\hline & 6-10 (\%) & $205(45.2)$ \\
\hline & $>10(\%)$ & $72(15.8)$ \\
\hline \multirow[t]{2}{*}{ Sex } & Male (\%) & $211(46.5)$ \\
\hline & Female (\%) & $243(53.5)$ \\
\hline \multicolumn{2}{|c|}{ Mean weight in Kg (Range) } & $21.78 \pm 8.6(6.0-52)$ \\
\hline \multicolumn{2}{|c|}{ Mean height in cm (Range) } & $114.2 \pm 21.3(54-160)$ \\
\hline \multicolumn{2}{|l|}{ Mean HAZ (Range) } & $-0.58 \pm 1.7(-7.8-8.2)$ \\
\hline \multicolumn{2}{|l|}{ Mean WAZ (Range) } & $-0.40 \pm 1.3(-4.8-6.2)$ \\
\hline \multicolumn{2}{|l|}{ Mean WHZ (Range) } & $0.06 \pm 1.5(-4.1-7.2)$ \\
\hline \multicolumn{2}{|c|}{ Mean temperature in ${ }^{\circ} \mathrm{C}$ (Range) } & $37.03 \pm 0.6(35.1-40.4)$ \\
\hline \multicolumn{2}{|c|}{ Mean haemoglobin in $\mathrm{g} / \mathrm{dL}$ (Range) } & $11.6 \pm 1.9(2.4-21.1)$ \\
\hline \multicolumn{2}{|c|}{ Prevalence $(\%)$ of fever (Temperature $>37.5^{\circ} \mathrm{C}$ ) } & 21.6 \\
\hline \multicolumn{2}{|c|}{ Prevalence (\%) of $P$. falciparum } & 36.6 \\
\hline \multicolumn{2}{|c|}{ Prevalence (\%) of stunting } & 17.1 \\
\hline \multicolumn{2}{|c|}{ Prevalence (\%) underweight } & 8.2 \\
\hline \multicolumn{2}{|c|}{ Prevalence (\%) of wasting } & 5.5 \\
\hline \multicolumn{2}{|c|}{ Prevalence (\%) of malnutrition } & 22.8 \\
\hline
\end{tabular}

(17.3\%. CI $=13.1-22.5 \%)$ and the difference in prevalence was significant at $P<0.01$. While stunting was significantly higher $(P<0.01)$ in males $(23.1 \%, \mathrm{CI}=$ $17.9-29.3 \%)$ than in females $(11.9 \%, \mathrm{CI}=8.4-16.6 \%)$, the difference in prevalence of underweight and wasting amongst the sexes was not significant $(P>0.05)$.

The prevalence of malnutrition was significantly highest $(P<0.05)$ in children in the less than or equal to 5 years age group $(29.5 \%, \mathrm{CI}=23.2-36.7 \%)$ when compared with the $6-10(18 \%, \mathrm{CI}=13.3-23.8 \%)$ and the $11-14$ years $(20.8 \%, C I=13.1-31.6 \%)$ age groups. Similarly, the prevalence of underweight was significantly highest $(P=0.01)$ in children in the $\leq 5$ years age group $(13.3 \%, \mathrm{CI}=9-19.2 \%)$, than their 6-10 (4.9\%, CI = 2.7$8.7 \%)$ and $11-14$ years old $(5.6 \%, \mathrm{CI}=2.2-13.4 \%)$ counterparts. On the other hand, a comparison of the prevalence of stunting and wasting amongst the different age groups revealed no significant differences (Table 2).

Amongst children in the less than or equal to 5 years age groups, although not statistically significant $(P=$ $0.15)$, malnutrition was most common in children aged between 1.1-3 years (37.5\%, CI = 27.2-49.1\%), when compared with those $\leq 1$ year $(25.5 \%, \mathrm{CI}=10.2-49.5 \%)$ and those in the $3.1-5$ years $(23.5 \%, \mathrm{CI}=15.8=33.6 \%)$ age groups.

The prevalence of severe stunting, severe wasting and severe underweight in the study population was $4.9 \%$ (22) $1.6 \%$ (7) and $1.8 \%$ (8) respectively.

\section{$P$. falciparum malaria and nutritional status}

Although not statistically significant $(\mathrm{P}>0.05)$, the prevalence of $P$. falciparum was higher in malnourished children (39.8\%), more especially in those stunted (42.9\%) and underweight $(43.2 \%)$ than their normal equivalent. On the other hand, $P$. falciparum parasite prevalence was lower in children who were wasted than those normal as shown in Fig. 1.

Similarly, the GMPD (geometric mean parasite density) $/ \mu \mathrm{L}$ of blood was higher in malnourished children (915.8) when compared with their well nourished counterparts (816.6) although the difference was not statistically significant $(P=0.81)$. Specifically, malaria parasite counts were highest in those wasted than those stunted, underweight and normal as shown in Fig. 2.

Following a comparison of the presence of clinical and asymptomatic malaria parasitaemia and nutritional status, the prevalence of CMP was significantly higher $(P<0.01)$ in malnourished children $(16.5 \%, \mathrm{CI}=10.6-24.9 \%)$ when compared with well nourished children $(6.9 \%, \mathrm{CI}=4.7$ $10.1 \%)$. On the other hand, the difference in prevalence of AMP in the different categories of children was none

Table 2 Effect of age and sex on the prevalence of the different forms of malnutrition

\begin{tabular}{|c|c|c|c|c|c|c|}
\hline \multirow[t]{2}{*}{ Parameter } & & \multirow[t]{2}{*}{$\mathrm{N}$} & \multirow[t]{2}{*}{ Malnourished \% (n) } & \multicolumn{3}{|c|}{ Forms of malnutrition } \\
\hline & & & & Stunted \% (n) & Underweight \% (n) & Wasted \% (n) \\
\hline \multirow[t]{2}{*}{ Sex } & Female & 243 & $17.3(42)$ & $11.9(29)$ & $6.6(16)$ & $7.4(18)$ \\
\hline & Male & 208 & $29.3(61)$ & $23.1(48)$ & $10.1(21)$ & $6.3(13)$ \\
\hline \multirow[t]{2}{*}{ Test } & $x^{2}$ & & 9.22 & 10.05 & 1.71 & 0.29 \\
\hline & $P$-value & & 0.002 & 0.002 & 0.19 & 0.59 \\
\hline \multirow[t]{3}{*}{ Age group in years } & $\leq 5$ & 173 & $29.5(51)$ & $19.7(34)$ & $13.3(23)$ & $9.2(16)$ \\
\hline & $6-10$ & 206 & $18(37)$ & $13.6(28)$ & $4.9(10)$ & $6.8(14)$ \\
\hline & $11-14$ & 72 & $20.8(15)$ & $20.8(15)$ & $5.6(4)$ & $1.4(1)$ \\
\hline \multirow[t]{2}{*}{ Test } & $x^{2}$ & & 7.23 & 3.32 & 9.14 & 0.44 \\
\hline & $P$-value & & 0.03 & 0.19 & 0.01 & 0.11 \\
\hline
\end{tabular}




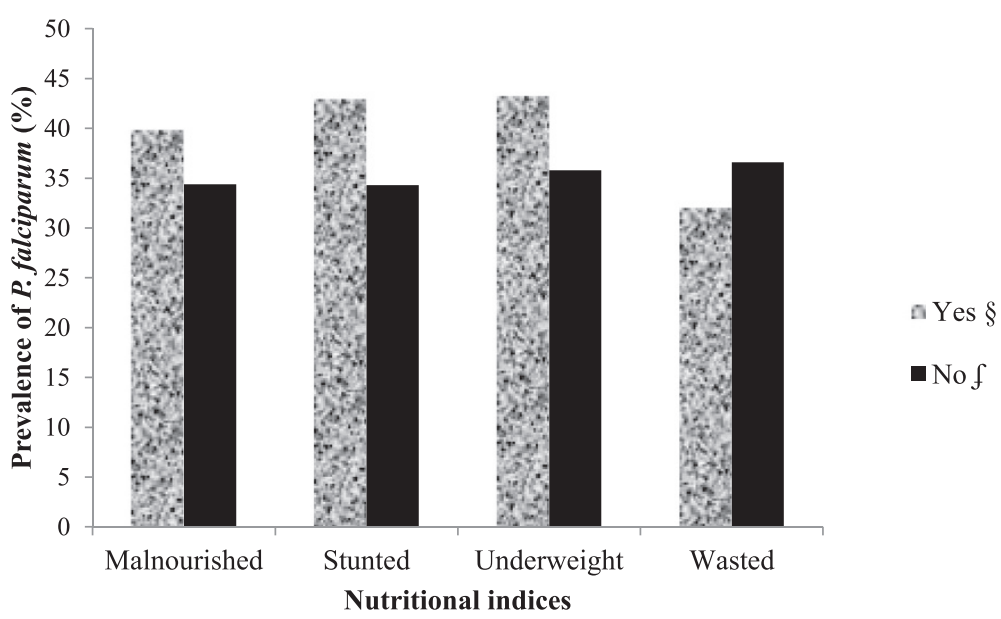

Fig. 1 Malaria parasite prevalence as affected by the different forms of malnutrition. § Prevalence of malaria parasite in malnourished children. f Prevalence of malaria parasite in normal children

significant as shown in Table 3. While CMP was significantly higher $(P<0.05)$ in children who were stunted $(16.9 \%, \mathrm{CI}=10.1-26.8 \%)$ and underweight $(21.6 \%, \mathrm{CI}=$ 11.4-37.2 \%) than their normal counterparts $(7.5 \%, \mathrm{CI}=$ $5.2-10.6 \% ; 8.2 \%, \mathrm{CI}=5.9-11.3 \%$ respectively), the prevalence of CMP was comparable $(P=0.78)$ in those wasted (Table 3).

\section{Clinical predictors of malnutrition}

A test of the full model against a constant only model was statistically significant $\left(\chi^{2}=22.79, \mathrm{df}=8, P=0.004\right)$ indicating that the independent variable sets reliably distinguished between malnourished and nourished children.
The binomial logistic regression model demonstrated sex $(P=0.006)$ and age group $1.1-3$ years $(P=0.03)$ as significant predictors of malnutrition as shown in Table 4. The age group 1.1-3 years was associated with 2 fold higher risk of being malnourished.

\section{Influence of nutritional status on anaemia severity}

Although not statistically significant $\left(\chi^{2}=3.5, P=0.06\right)$, the prevalence of anaemia was higher in malnourished children than their well nourished counterparts. Mild, moderate and severe anaemia were significantly highest $\left(x^{2}=9.89, P=0.02\right)$ in malnourished than those normal (Fig. 3).

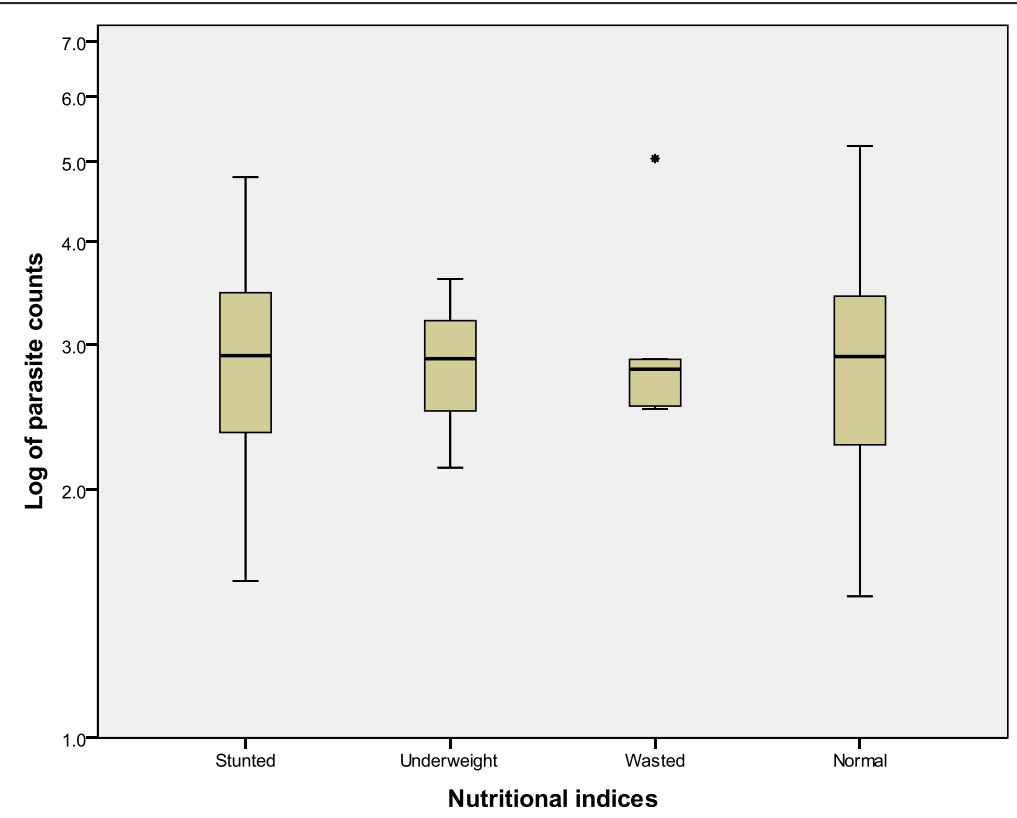

Fig. 2 A comparison of $P$. falciparum parasite counts as affected by nutritional indices 
Table 3 Prevalence of clinical and asymptomatic malaria parasitaemia as affected by nutritional status

\begin{tabular}{|c|c|c|c|c|c|c|}
\hline \multirow[t]{3}{*}{ Parameter } & \multirow[t]{3}{*}{ Status } & \multirow[t]{3}{*}{$N$} & \multicolumn{2}{|c|}{$\begin{array}{l}\text { Clinical malaria } \\
\text { parasitaemia } \\
\text { prevalence }\end{array}$} & \multicolumn{2}{|c|}{$\begin{array}{l}\text { Asymptomatic } \\
\text { malaria parasitaemia } \\
\text { prevalence }\end{array}$} \\
\hline & & & $\%(n)$ & $x^{2}$ & $\%(n)$ & $x^{2}$ \\
\hline & & & & $P$-value & & $P$-value \\
\hline \multirow[t]{2}{*}{ Malnourished } & Yes & 103 & $16.5(17)$ & 8.88 & $23.3(24)$ & 0.68 \\
\hline & No & 348 & $6.9(24)$ & 0.003 & $27.4(95)$ & 0.41 \\
\hline \multirow[t]{2}{*}{ Stunted } & Yes & 77 & 16.9 (13) & 6.59 & $26.0(20)$ & 0.01 \\
\hline & No & 374 & $7.5(28)$ & 0.01 & $26.2(98)$ & 0.91 \\
\hline \multirow[t]{2}{*}{ Underweight } & Yes & 37 & $21.6(8)$ & 7.28 & $21.6(8)$ & 0.59 \\
\hline & No & 414 & $8.2(34)$ & 0.007 & 27.5 (114) & 0.44 \\
\hline \multirow[t]{2}{*}{ Wasted } & Yes & 31 & $6.5(2)$ & 0.08 & $22.6(7)$ & 0.08 \\
\hline & No & 420 & $9.7(41)$ & 0.78 & 26.7 (112) & 0.77 \\
\hline
\end{tabular}

As revealed in Table 5, in children who were malaria parasite negative, the prevalence of anaemia as well as mild, moderate and severe anaemia were significantly higher $(P=0.04$ and $P=0.001$ respectively) in malnourished than in well nourished children. On the other hand, no statistically significant difference in prevalence of anaemia and severities of anaemia $(P=0.69$ and $P=0.95$ respectively) were observed in malnourished and well nourished children who were malaria parasite positive.

\section{Discussion}

The nutritional status of a person is the most important determinant factor in the health status of that individual, especially children and adolescents for a period of growth. The fundamental relationship between undernutrition and malaria is multifaceted. While some findings show that undernutrition increases susceptibility to malaria [6], others indicate that malaria increases the likelihood of a child having poor nutritional outcomes [22]. This study

Table 4 Binomial logistic regression analysis examining clinical factors associated with malnutrition ${ }^{a}$ in children

\begin{tabular}{lccc}
\hline Factors & Odds ratio (OR) & $95 \% \mathrm{Cl}$ & P-value \\
\hline${ }^{6}$ Male & 1.91 & $1.20-2.04$ & 0.006 \\
Age groups & & & 0.048 \\
Age $\leq 1$ year & 1.30 & $0.38-4.82$ & 0.64 \\
Age 1.1 - 3 year & 2.18 & $1.08-4.40$ & 0.03 \\
Age 3.1 - 5 years & 1.08 & $0.54-2.18$ & 0.83 \\
Age 5.1 - 9 years & 0.82 & $0.44-1.54$ & 0.53 \\
${ }^{c}$ Splenomegaly & 0.78 & $0.39-1.5$ & 0.49 \\
${ }^{d}$ Anaemia & 1.41 & $0.84-2.36$ & 0.19 \\
${ }^{e}$ Malaria Parasite positive & 1.35 & $0.70-1.83$ & 0.61 \\
\hline
\end{tabular}

${ }^{a}$ Malnutrition: children with a standard deviation score of $<-2$ for WA/HA/WH ${ }^{b}$ Male $=1$; Female $=0$

'Splenomegaly $=1$; Normal $=0$

${ }^{d}$ Anaemia $(\mathrm{Hb}<11 \mathrm{~g} / \mathrm{dL})=1$; Non anaemic $(\mathrm{Hb} \geq 11 \mathrm{~g} / \mathrm{dL})=0$

${ }^{e}$ Malaria parasite positive $=1 ;$ Negative $=0$ investigated the prevalence, intensity and predictors of malnutrition in children living in an area meso endemic for malaria as well as its influence on the prevalence of asymptomatic and clinical malaria parasitaemia and anaemia severity.

Malnutrition was common $(22.8 \%)$ in the community with an overall prevalence of $17.1 \%$ for stunting, the most common form of malnutrition. This is lower than the $58.1 \%$ observed in children of the same community in 2006 by Nkuo-Akenji et al. [23] as well as $30.2 \%$ in Dibanda in the same Mount Cameroon area by Mbuh and Nembo [24] and 38.64\% for stunting by Tine et al. [25] in Senegal. The decline in the prevalence of malnutrition in the community may be linked to the recorded decline in malaria parasite prevalence observed in the population over the years and the regular de-worming campaign carried out in school children by the Ministry of Public Health in Cameroon. Infectious diseases have been reported to have a negative impact on nutritional status, resulting in a vicious cycle of under nutrition and infection $[4,5]$. Furthermore, the acquisition of knowledge by caregivers/parents on the health and nutritional status of their children following the education on the outcome of the previous study and knowledge on proper feeding habits may have played a significant role in improving the nutritional status of the children. Although an improvement in the nutritional status was observed analyses of the mean HAZ, WAZ and WHZ scores revealed that majority of the children did not attain their maximum growth potential as all three mean scores were less than 1 each. Children whose weight-for-age is less than -1 SD are at increased risk of death [26].

Malnutrition was significantly higher in males (29.3\%) than females $(17.3 \%)$ and the binomial logistic regression analysis revealed male children were significantly at odds of being malnourished than females. More specifically, stunting was significantly higher in males while the prevalence of wasting although not significant was common in females than males. The observation is in line with Kamugisha et al. [27] who reported that stunting and underweight were common among males than females in all age groups. In addition, in a meta-analysis of 16 demographic and health surveys in Sub-Saharan Africa, boys were reported to be more stunted than girls [28]. The authors attributed it to the biological vulnerability of male children than the female children. This vulnerability may be a contributing factor to the higher malaria morbidity reported in male children in the Mount Cameroon area $[29,30]$ hence increasing the likelihood of male children having poor nutritional outcome.

Severe nutritional conditions ( $\mathrm{z}$ score less than -3 ) such as underweight and wasting were uncommon in the study population, while the presence of severe stunting $(4.9 \%)$ was comparable to that reported by Ehrhardt 


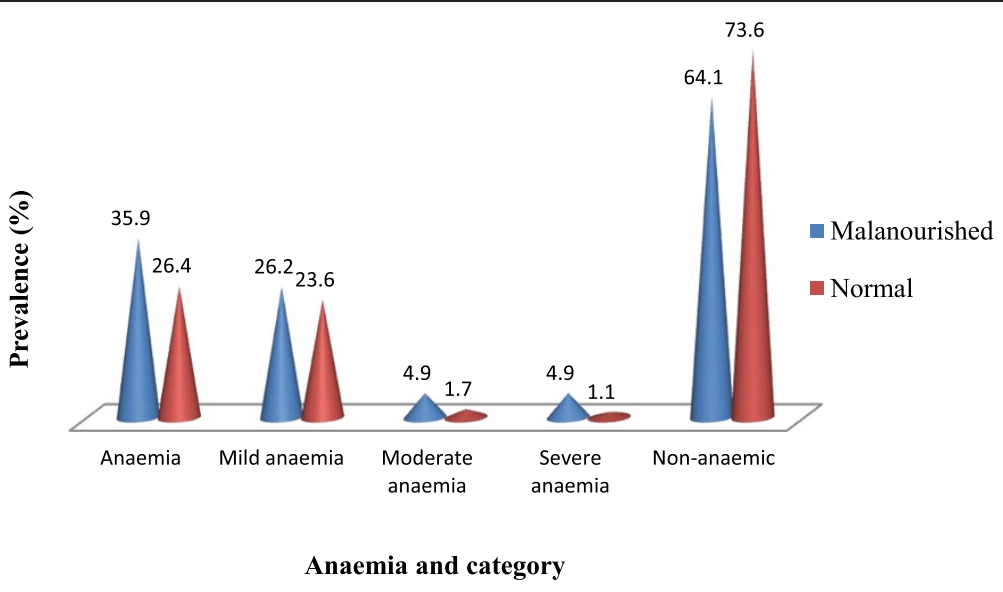

Fig. 3 Prevalence of anaemia and severity as affected by nutritional status

et al. [31] in African children (5.8\%). The presence of severe stunting in the community which probably reflects long standing processes affecting growth of the children adversely is a cause for concern as stunting has been associated with impaired cognitive development [8]. While Pongou et al. [32] has reported a positive effect of maternal education and health seeking behaviour on child nutritional status in Cameroon, there is therefore the need for immediate interventions on factors directly linked to growth such as; feeding habits, nutritional intake, education of caregiver/family head and proper health seeking behaviours which may go to reverse the effects of malnutrition.

The observation of age as a significant predictor of malnutrition is not unusual. In line with Ehrhardt et al. [31], the prevalence of malnutrition was significantly highest in children $\leq 5$ years than their counterparts. The prevalence of chronic malnutrition in the under five (19.7\%) is similar to those obtained by Maketa et al. [33] in the Democratic Republic of Congo. However, the prevalence values for stunting, underweight and wasting were lower when compared with children of the same age group in Ethiopia [34]. All three forms of malnutrition had similarities in the age pattern of distribution nevertheless, only the difference in prevalence of underweight was statistically significant. Amongst children under five years of age, those between 1.1 to 3 years of age had a 2 fold risk of being malnourished than the others as revealed in the binomial regression analysis. This is critical as a child's optimal growth occurs during the first 2 years of life. Some of the children in this age group include those on transition from breast milk to complementary foods which when given may not be adequate both in nutrient content and amount of intake to meet the requirements for growth. In as much as children in this age group are at high risk of malaria, the increased risk of gastrointestinal infection associated with the introduction of complementary foods may also contribute to malnutrition.

Although the relationship between the presence of malaria parasite and nutritional status was not significant, malnourished children were 1.35 times at odds of

Table 5 Prevalence of anaemia and severity as affected by malaria parasite and nutritional status

\begin{tabular}{|c|c|c|c|c|c|c|}
\hline \multirow[t]{4}{*}{ Parameter } & \multicolumn{6}{|c|}{ Malaria parasite status } \\
\hline & \multicolumn{3}{|c|}{$\begin{array}{l}\text { Positive } \\
\text { Nutritional status }\end{array}$} & \multicolumn{3}{|c|}{$\begin{array}{l}\text { Negative } \\
\text { Nutritional status }\end{array}$} \\
\hline & Malnourished & Normal & $x^{2}$ & Malnourished & Normal & $x^{2}$ \\
\hline & $\%(n)$ & $\%(n)$ & $\mathrm{P}$ & $\%(n)$ & $\%(n)$ & $P$ \\
\hline N & 41 & 119 & & 62 & 227 & \\
\hline \multirow[t]{2}{*}{ Anaemia } & $43.9(18)$ & $40.3(48)$ & 0.16 & $30.6(19)$ & $18.5(42)$ & 4.31 \\
\hline & & & 0.69 & & & 0.04 \\
\hline Mild & $39.0(16)$ & $35.3(42)$ & 0.36 & $17.7(11)$ & $16.7(38)$ & 15.50 \\
\hline Moderate & $2.4(1)$ & $3.4(4)$ & & $6.5(4)$ & $0.9(2)$ & \\
\hline Severe & $2.4(1)$ & $1.7(2)$ & 0.95 & $6.5(4)$ & $0.9(2)$ & 0.001 \\
\hline Non-anaemic & $56.1(23)$ & $59.7(71)$ & & $69.4(43)$ & $81.5(185)$ & \\
\hline
\end{tabular}


being malaria parasite positive and had higher GMPD than normal children. The manifestation of chronic and acute nutritional deficits which results in stunting and wasting respectively influenced the prevalence of malaria parasite in the population. Overall, while children who were stunted and underweight had a higher prevalence of malaria parasite, those wasted had a lower prevalence. On closer examination, in line with Crookston et al. [35], no significant relationship was observed between the presence of asymptomatic malaria parasitaemia and stunting as well as the other forms of malnutrition. On the other hand, children who were stunted and underweight had significantly higher prevalence of clinical malaria parasitaemia. In the same light Friedman et al. [11] in Kenya reported stunting to be associated with clinical malaria. The nutritional inadequacies of these children may have influenced their vulnerability to the expression of clinical infection as Caulfield et al. [6] suggested malnutrition influences the susceptibility to and manifestation of malaria.

Wasting which is a form of acute malnutrition has been reported as a risk factor for malaria following the low humoral responses to malarial antigens in wasted children [36]. Interestingly, findings from the study revealed the prevalence of malaria parasitaemia was lower in those wasted than in the well nourished. In addition to the lower clinical and asymptomatic malaria parasitaemia observed (Table 3), children who were wasted also had a higher parasitaemia when compared with their counterparts (Fig. 2). This probably suggests that children with acute malnutrition in this meso endemic area were able to regulate or were protected to some extent against infection per se, its clinical presentation but not the parasite densities. However these findings need further investigation in a holo endemic area to assert the role of acute malnutrition in malaria endemic areas.

Malnutrition is known to be a leading factor to anaemia and findings from the study revealed mild, moderate and severe anaemia to be significantly higher in malnourished children. The multivariate analysis revealed anaemic children were 1.4 times at odds of being malnourished than their well nourished counterparts but it was not a statistically significant risk factor when compared with being male and of the $1.1-3$ years age group. However, the significant influence of malnutrition on the prevalence and severity of anaemia was only discernible in children who were malaria parasite negative while its additive influence was insignificant in those positive (Table 5). While these findings demonstrate the significant contribution of malnutrition to the presence and severity of anaemia in the population, it also highlights anaemia due to $P$. falciparum infection as a significant public health problem. Hence in malaria endemic areas there is a need for integrated interventions targeting both malnutrition and malaria so as to improve upon the health and growth potential of the children.

\section{Conclusions}

The presence of stunting in the community significantly augmented the prevalence and clinical presentation of Plasmodium infection while wasting ensured some protection per se. Being male and 1.1 to 3 years of age are significant clinical risk factors of malnutrition and malnutrition enhanced the severity of anaemia especially in malaria parasite negative children. Hence the health and growth potential of children in this meso endemic area can be improved upon by integrating interventions directly linked to growth to the malaria and helminth control programmes already in place.

\section{Abbreviations}

AMP: asymptomatic malaria parasitaemia; Cl: $95 \%$ confidence interval; CMP: clinical malaria parasitaemia; GMPD: geometric mean parasite density; HAZ: height-for-age $z_{;} \mathrm{Hb}$ : haemoglobin; WAZ: weight-for-age $z_{;}$WBC: white blood cell; WHZ: weight-for-height $\mathrm{Z}$.

\section{Competing interests}

The authors declare that they have no competing interests.

\section{Authors' contributions}

IUNS was involved in all phases of the study, including study design, data collection, data analysis, interpretation, and write-up of the manuscript; OSMB participated in data collection, supervision and revision of the manuscript; HKK participated in supervision and revision of the manuscript; TRN participated in data collection and laboratory analysis; TN-A participated in supervision and revision of the manuscript. All authors read and approved the final manuscript.

\section{Authors' information}

IUNS: PhD and Lecturer of Parasitology. OSMB: PhD and Lecturer in Physiology. HKK: PhD and Associate Professor of Medical Parasitology. TRN: MSC in Parasitology. TN-A PhD and Professor of Parasitology.

\section{Acknowledgements}

The authors appreciate the support and cooperation of the parents and guardians of the children in the Muea community, the staff of the Muea Health Centre and medical students from the Faculty of Health Sciences, University of Buea who took part in the study. This work was supported by the staff development grant and special fund for research and modernization given to authors by the Government of Cameroon.

\section{Author details}

${ }^{1}$ Department of Zoology and Animal Physiology, University of Buea, Buea, Cameroon. ${ }^{2}$ Department of Microbiology and Parasitology, University of Buea, Buea, Cameroon.

Received: 16 May 2015 Accepted: 30 October 2015

Published online: 05 November 2015

\section{References}

1. Nubé M, Sonneveld BG. The geographical distribution of underweight children in Africa. Bull World Health Organ. 2005;83:764-70.

2. Katona P, Katona-Apte J. The interaction between nutrition and infection. Clin Infect Dis. 2008;46:1582-8.

3. Maggini $S$, Wenzlaff $S$, Hornig D. Essential role of vitamin $C$ and zinc in child immunity and health. J Int Med Res. 2010;38:386-414.

4. Scrimshaw NS, SanGiovanni JP. Synergism of nutrition, infection, and immunity: an overview. Am J Clin Nutr. 1997;66(Suppl):464-77.

5. Keusch GT. The history of nutrition: malnutrition, infection and immunity. J Nutr. 2003;133(Suppl):336S-40S. 
6. Caulfield L, Richard SA, Black RE. Under nutrition as an underlying cause of malaria morbidity and mortality in children less than five years old. Am J Trop Med Hyg. 2004;71 suppl 2:55-63.

7. Grantham-McGregor SM, Fernald LC, Sethuraman K. Effects of health and nutrition on cognitive and behavioral development in children in the first three years of life. Part 1: Low birthweight, breastfeeding, and protein energy undernutrition. Food Nutr Bull. 1999;20:53-75.

8. Martorell R, Rivera J, Kaplowitz H, Pollitt E. Long-term consequences of growth retardation during early childhood. In: Hernandez M, Argente J, editors. Human growth: Basic and clinical aspects. Amsterdam: Elsevier Science; 1992. p. 143-9.

9. Garenne M, Maire B, Fontaine O, Briend A. Distributions of mortality risk attributable to low nutritional status in Niakhar. Senegal J Nutr. 2006:136:2893-900.

10. Tshikuka JG, Gray-Donald K, Scott M, Olela KN. Relationship of childhood protein-energy malnutrition and parasite infections in an urban African setting. Trop Med Int Health. 1997;2:374-82.

11. Friedman JF, Kwena AM, Mirel LB, Kariuki SK, Terlouw DJ, Phillips-Howard PA, et al. Malaria and nutritional status among pre-school children: results from cross-sectional surveys in western Kenya. Am J Trop Med Hyg. 2005;73:698-704

12. Bigoga JD, Manga L, Titanji VPK, Coetzee M, Leke RGF. Malaria vectors and transmission dynamics in coastal south-western Cameroon. Malar J. 2007;6:5.

13. Nkuo-Akenji T, Ntonifor NN, Ching JK, Kimbi HK, Ndamukong KN, Anong DA, et al. Evaluating a malaria intervention strategy using knowledge, practices and coverage surveys in rural Bolifamba, South West Cameroon. Trans R Soc Trop Med Hyg. 2005;99:325-32.

14. Sumbele IUN, Ning TR, Bopda OSM, Nkuo-Akenji T. Variation in malariometric and red cell indices in children in the Mount Cameroon area following enhanced malaria control measures: evidence from a repeated cross-sectional study. Malar J. 2014;13:334.

15. Bryan FJ. The design and analysis of research studies. University of Otago, Uk: Cambridge University Press; 1992.

16. Kimbi HK, Sumbele IUN, Nweboh M, Anchang-Kimbi JK, Lum E, Nana N, et al. Malaria and haematologic parameters of pupils at different altitudes along the slope of Mount Cameroon: a cross-sectional study. Malar J. 2013;12:193.

17. Gilles HM. Pathology of Malaria: Handbook of Malaria Infection in the Tropics. Italy: Italian Association Amicidi Raoul Follerau (AIFO); 1997.

18. WHO. WHO child growth standards: length/height-for-age, weight-for-age, weight-for-length, weight-for-height and body mass index-for-age. Geneva: World Health Organization; 2006.

19. Calis JCJ, Phiri KS, Faragher BE, Brabin BJ, Bates I, Cuevas LE, et al. Severe Anaemia in Malawian Children. N Engl J Med. 2008;358:888-99.

20. Cheesbrough M. District laboratory practice in tropical countries. Cambridge University Press: Part1\& 2; 2009.

21. Trape JF. Rapid evaluation of malaria parasite density and standardization of thick smear examination for epidemiological investigations. Trans R Soc Trop Med Hyg. 1985;79:181-4.

22. Nyakeriga AM, Troye-Blomberg M, Chemtai AK, Marsh K, Williams TN. Malaria and nutritional status in children living on the coast of Kenya. Am J Clin Nutr. 2004;80:1604-10.

23. Nkuo-Akenji TN, Sumbele I, Mankah EN, Njunda AL, Samje M, Kamga L. The burden of malaria and malnutrition among children less than 14 years of age in a rural village of Cameroon. AJFAND. 2008;8:252-64.

24. Mbuh JV, Nembu NE. Malnutrition and intestinal helminth infections in schoolchildren from Dibanda, Cameroon. J Helminthol. 2013;87(1):46-51.

25. Tine RCK, Ndiaye M, Hansson HH, Ndour CT, Faye B, Alifrangis $M$, et al. The association between malaria parasitaemia, erythrocyte polymorphisms, malnutrition and anaemia in children less than 10 years in Senegal: a case control study. BMC Res Notes. 2012;5:565.

26. Caulfield LE, Richard SA, Rivera JA, Musgrove P, Black RE. Stunting, wasting, and micronutrient deficiency disorders. In: Jamison D, Breman J, Measham A, Alleyne G, Claeson M, Evans D, et al., editors. Disease control priorities in developing countries. 2nd ed. Washington, DC: Oxford University Press; 2006. p. 551-67.

27. Kamugisha ML, Crawford N, Savaell Z, Msangeni H, Massaga JJ, Mmbando $\mathrm{BP}$, et al. Malaria and nutritional status in children living in the East Usambara Mountains, north-eastern Tanzania. Tanzania Health Res Bull. 2006;8:56-61.
28. Wamani H, Astrom A, Peterson S, Tumwine J, Tylleskar T. Boys are more stunted than girls in Sub-Saharan Africa: a meta-analysis of 16 demographic and health surveys. BMC Pediatr. 2007;7:17.

29. Kimbi HK, Nana Y, Sumbele IUN, Anchang-Kimbi JK, Lum E, Tonga C. Environmental factors and preventive methods against malaria parasite prevalence in rural Bomaka and urban Molyko. Southwest Cameroon J Bacteriol Parasitol. 2013;4:1.

30. Ndamukong-Nyanga JL, Kimbi HK, Sumbele IUN, Emmaculate L, Nweboh MN, Nana Y, et al. Socio-demographic and environmental factors influencing asymptomatic malaria and anaemia incidence among school children in Fako division, Southwest Cameroon. BJMMR. 2014;4(20):3814-27.

31. Ehrhardt S, Burchard GD, Mantel C, Cramer JP, Kaiser S, Kubo M, et al. Malaria, anemia, and malnutrition in African children-defining intervention priorities. J Infect Dis. 2006;194:108-14.

32. Pongou R, Ezzati M, Salomon JA. Household and community socioeconomic and environmental determinants of child nutritional status in Cameroon. BMC Public Health. 2006:6:98.

33. Maketa V, Mavoko HM, Luz Rl, Zanga J, Lubiba J, Kalonji A, et al. The relationship between Plasmodium infection, anaemia and nutritional status in asymptomatic children aged under five years living in stable transmission zones in Kinshasa, Democratic Republic of Congo. Malar J. 2015;14:83.

34. Asfaw M, Wondaferash M, Taha M, Dube L. Prevalence of undernutrition and associated factors among children aged between six to fifty nine months in Bule Hora district, South Ethiopia. BMC Public Health. 2015;15:41.

35. Crookston BT, Alder SC, Boakye I, Merrill RM, Amuasi JH, Porucznik CA, et al. Exploring the relationship between chronic undernutrition and asymptomatic malaria in Ghanaian children. Malar J. 2010;9:39.

36. Genton B, Al-Yaman F, Ginny M, Taraika J, Alpers MP. Relation of anthropometry to malaria morbidity and immunity in Papua New Guinean children. Am J Clin Nutr. 1998;68:734-41.

\section{Submit your next manuscript to BioMed Central and take full advantage of:}

- Convenient online submission

- Thorough peer review

- No space constraints or color figure charges

- Immediate publication on acceptance

- Inclusion in PubMed, CAS, Scopus and Google Scholar

- Research which is freely available for redistribution

Submit your manuscript at www.biomedcentral.com/submit
C BioMed Central 